\title{
Decadal demographic trends of a long-lived temperate encrusting sponge
}

\author{
N. Teixidó ${ }^{1,2, *}$, M. C. Pineda ${ }^{2,3}$, J. Garrabou ${ }^{2,4}$ \\ ${ }^{1}$ Centre for Advanced Studies of Blanes (CEAB-CSIC), Accés Cala Sant Francesc 14, 17300 Blanes, Girona, Spain \\ ${ }^{2}$ Centre d'Océanologie de Marseille, Universite de la Mediterranee, CNRS - UMR 6540 DIMAR, Station Marine d'Endoume, \\ rue Batterie des Lions, 13007 Marseille, France \\ ${ }^{3}$ Present address: Department of Animal Biology (Invertebrates), Faculty of Biology, University of Barcelona, \\ 645 Diagonal Avenue, 08028 Barcelona, Spain
}

${ }^{4}$ Present address: Institute of Marine Sciences of Barcelona (ICM-CSIC), Passeig Marítim de la Barceloneta 37-49, 08003 Barcelona, Spain

\begin{abstract}
Demographic data play a central role in determining the overall dynamics of species and forecasting the effects of global change. We examined a decadal pattern of population dynamics and its underlying mechanisms in a population of the encrusting sponge Crambe crambe. A photographic series monitored yearly for 14 yr (1993 to 2007) was analyzed. A total of 133 genets and 157 ramets were individually identified and followed over 14 yr to record their fates: survivorship, partial mortality, recruitment via larvae, asexual events (fission and fusion), and growth. The number of genets varied little over time; their survival was high and differed significantly with size class $(52,82$, and $100 \%$ for size classes $0-250,250-700$, and $>700 \mathrm{~mm}^{2}$, respectively), while recruitment via larvae was very low. Overall, the population was characterized by the inputs and outputs of asexual ramets. Patterns of partial mortality were (1) significantly related to size and (2) did not differ significantly among years, and (3) no patch $>500 \mathrm{~mm}^{2}$ suffered any type of mortality. We give the first evidence that net growth over more than a decade was close to zero for the larger specimens, while the smallest specimens exhibited the highest growth rates, quadrupling in size over $14 \mathrm{yr}$. Low mortality combined with the slow growth of large specimens indicates that C. crambe may live for several decades. This study provides rigorous baseline information necessary to uncover general patterns in the demography of marine sessile species and better predict the long-term fate of populations.
\end{abstract}

KEY WORDS: Crambe crambe $\cdot$ Life history $\cdot$ Long-term studies $\cdot$ Modular animals $\cdot$ Population dynamics

\section{INTRODUCTION}

The long-term survival of sessile species, including plants and marine sessile organisms, is determined by their vital rates, e.g. reproduction, recruitment, growth, and mortality (Hall \& Hughes 1996). These processes can be difficult to estimate as they may vary significantly over space and time (Connell et al. 1997, Adondakis \& Venable 2004, Miriti 2007). Populations of slow-growing, long-lived sessile species do not often undergo marked declines and even populations with little or no regeneration capacity are projected to survive for decades or even centuries (Stephenson 1994,
Linares et al. 2007, Miriti 2007). In particular, when rates of change are very slow or when crucial events occur rarely (e.g. severe disturbances or exceptional recruitment), detecting the effect of these on populations requires long-term records (Connell et al. 1997, Rees et al. 2001). Therefore, detailed long-term studies following the fate of species may be the only reliable way to uncover general patterns in the demography of sessile species and better predict the long-term fate of populations. In contrast to terrestrial plant systems, such data are scarce for marine benthic habitats and there is little empirical work on the population dynamics of long-lived marine sessile species. 
Clonal benthic invertebrates are composed of repeated 'modules' (polyps or zooids), which are derived asexually by vegetative growth. Sponges are not clonal organisms from a morphological point of view because of the lack of identifiable modules. However, they are ecologically equivalent to clonal groups since they share with them the potential for indeterminate growth, both fusion and fission, and the capacity to recover from partial mortality (Jackson 1979, Hughes 1989, Pronzato \& Manconi 1995). Generally, life history attributes of clonal animals (e.g. reproduction, competition, recovery, and survival) have been observed to be highly related to colony size (Hughes \& Jackson 1985). In clonal species, the genet is considered to be the sum of all the genetically identical modules coming from the same zygote, whereas a ramet is a physiologically independent part of a genet (sensu Harper 1977). These features make the demographic analyses of clonal species difficult. However, accurate demography for both genets and ramets is necessary to understand the population dynamics and life history evolution of these species. Ramet demography gives a perspective on the long-term persistence of a population, whereas genet demography provides basic information about changes in the genetic population structure and evolutionary processes (Silander 1985, Tanner 2001). Moreover, patterns of ramets and genets may differ considerably within a given population (Eriksson 1993).

In this study, we present the first long-term demographic analysis of genets and ramets with hightemporal resolution on a long-lived sponge. Studies assessing population dynamics of sponges have shown long lifespans, slow growth, and low recruitment (Dayton 1979, Ayling 1983, Pansini \& Pronzato 1990, Pronzato \& Manconi 1995). The existence of large individuals also suggests longevity (Sarà 1970, Ayling 1983, Pansini \& Pronzato 1990), estimated to reach several decades or even centuries (Dayton 1979, Leys \& Lauzon 1998). As they persist for such long time periods, sponges are thought to greatly influence other benthic community members (Bergquist 1978, Wulff 2006). Therefore, a detailed understanding of the life cycle of such species and the long-term temporal variation in their vital rates is crucial, not only to comprehend the mechanisms underlying their dynamics, but also for the effective management and conservation of ecosystems.

We investigate the population dynamics of the sponge Crambe crambe over 14 yr on a north-facing sublittoral wall in the NW Mediterranean Sea. For this purpose, a photographic series of permanent plots monitored yearly (1993 to 2007) was analyzed. Different parameters of demographic processes (population structure, survivorship, recruitment, partial and whole mortality, fission and fusion events, and growth) were recorded. The results of the present study offer the first detailed, long-term data providing new insights into the life history traits of this species. This work attempts to contribute to the general knowledge of marine communities characterized by long-lived species.

\section{MATERIALS AND METHODS}

Study species. Crambe crambe (Schmidt, 1862) is a Poecilosclerid red-orange encrusting sponge, which can reach surface areas of $0.5 \mathrm{~m}^{2}$. It is one of the characteristic species of all the littoral communities in the western Mediterranean (Boury-Esnault 1971, Uriz et al. 1992, 1998), but is also present in the Aegean and Levantine seas in the eastern Mediterranean (Voultsiadou 2005), the Adriatic Sea (Schmidt 1862), and on the Atlantic coast of Portugal and the Canary Islands (Duran et al. 2004). This sponge inhabits both photophilic and sciaphilous habitats with a depth range from 1 to $60 \mathrm{~m}$ (Uriz et al. 1992). C. crambe is one of the most well-known sponges, through its biological and ecological characteristics (Turon et al. 1996, Becerro et al. 1997, Uriz et al. 1998).

Crambe crambe is a hermaphrodite and viviparous species, releasing lecithotrophic larvae from the end of July to the end of August (Uriz et al. 1998). Asexual processes (fission and fusion) have been regularly observed (Turon et al. 1998, Garrabou \& Zabala 2001). Two previous studies where data was collected over 2 yr show that this sponge grows slowly (Turon et al. 1998, Garrabou \& Zabala 2001).

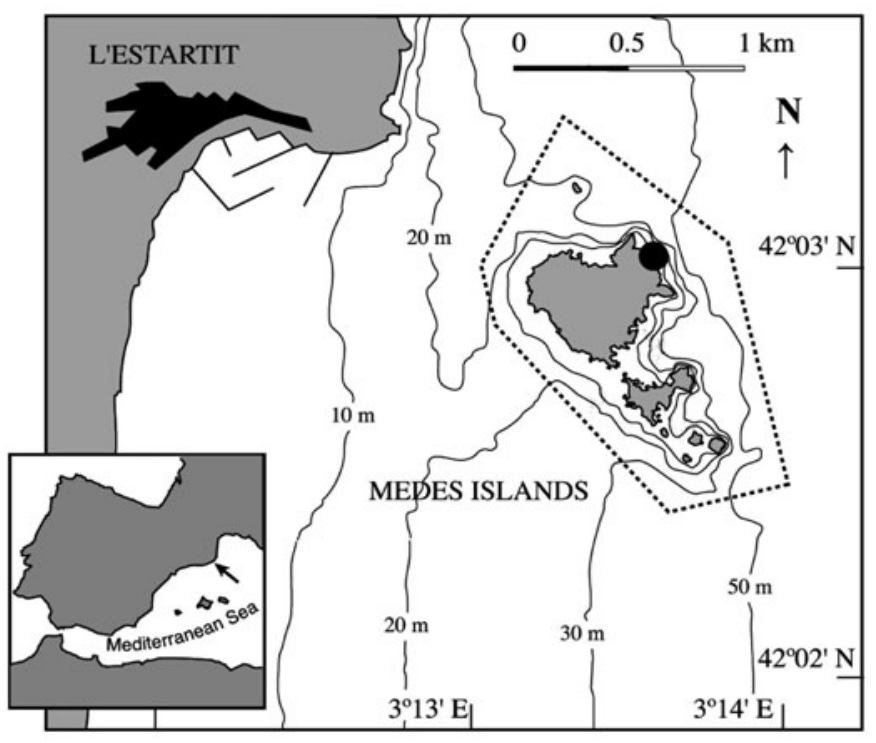

Fig 1. Map of the study site 'Pota de Llop' in the Medes Island Marine Protected Area $\left(42^{\circ} 3^{\prime} \mathrm{N}, 3^{\circ} 13^{\prime} \mathrm{E}\right.$, NE Spain), NW Mediterranean Sea 
Study area. A population of Crambe crambe was studied at one locality in the NW Mediterranean Sea: La Pota de Llop, in the Medes Island Marine Protected Area $\left(42^{\circ} 3^{\prime} \mathrm{N}, 3^{\circ} 13^{\prime} \mathrm{E}, \mathrm{NE}\right.$ Spain) (Fig. 1). The study population is found on a north-facing sublittoral wall and is distributed in a shaded habitat, between 12 and $16 \mathrm{~m}$ depth. The study site is characterized by the codominance of perennial animals (mainly encrusting sponges, cnidarians, bryozoans and compound ascidians) and encrusting coralline algal species. The rock surface is partially covered by a canopy of seasonal fleshy algae and soft hydrozoans and bryozoans during the spring and summer months (for detailed information see Gili \& Ros 1985, Garrabou et al. 2002).

Study design and photo sampling. Thirty-two permanent frames were monitored photographically over a 14 yr period (1993 to 2007) at intervals ranging from $\sim 4$ mo to annually. These frames were installed within a $60 \mathrm{~m}^{2}$ sampling area with a depth range of 12 to $16 \mathrm{~m}$. The photo frames were treated as statistical replicates in a repeated-measures design testing for differences among time. The pictures were taken with a Nikonos $\mathrm{V}$ camera (Nikon) equipped with UW $28 \mathrm{~mm}$ and closeup lenses from 1993 to 2005. From 2006 onward, a Nikon D70S digital SLR camera fitted with a Nikkor $20 \mathrm{~mm}$ DX lens $(3000 \times 2000$ pixels resolution $)$ in a Subal D70S housing was used. Lighting was achieved by 2 electronic strobes fitted with diffusers (Nikonos SB 105 and various Sea \& Sea strobes). The permanent frames were marked with 2 plastic clips attached to the substrate (50 to $70 \mathrm{~cm}$ apart). The clips together with a PVC custom-built fixed the camera ensuring that photographs were obtained in the same position and focal distance (Garrabou \& Zabala 2001). Each $35 \mathrm{~mm}$ frame recorded an area of $310 \mathrm{~cm}^{2}$ and each digital frame recorded an area of $575 \mathrm{~cm}^{2}$, respectively. We restricted our analyses to the $310 \mathrm{~cm}^{2}$ initial area despite the larger area covered by the digital camera to ensure the same measurements over time. For the present study, we selected the photo-graphs taken yearly in winter (when available), as this season showed the lowest vegetation coverage and the specimens of Crambe crambe were not hidden. A total of 480 photographs were analyzed and are available online (http://doi.pangea.de) (see Appendix 1, (available as an electronic supplement at www.int-res.com/ articles/suppl/m375p113_app.pdf, for further details).

Demographic analysis. Demographic parameters were quantified using digital images, which, for the color slides, were obtained by scanning the originals (300 dpi, $1632 \times 1080$ pixels resolution). All specimens analyzed were individually labeled in Adobe Photoshop 7.0. We defined a specimen (= genet) as any physically separate patch of sponge growing independently of its neighbors. Before any measurement was performed, we first observed each specimen and identified any fission and fusion events throughout the $14 \mathrm{yr}$ study period. All patches originating from any asexual event were scored as different fragments (= ramets) of the same specimen. Therefore, a specimen could have 1 or more fragments depending on the number of fission and fusion events. Finally, after tracking the life history of each specimen and their ramets throughout the study period, they were labeled and further analyzed. A total of 133 genets and 157 ramets present at the start of the study (1993) were individually identified and followed throughout 14 yr to record their fates: survivorship, partial mortality, recruitment via larvae, asexual events (fission and fusion), and growth.

Population size distribution. The population structure of Crambe crambe was determined by quantifying ramet abundance and size-frequency distribution at the start (1993) and end (2007) of the study. These patches were assigned to 1 of 11 size classes (0-100, $100-200,200-300, \ldots$ and $>1000 \mathrm{~mm}^{2}$ ) in order to provide a detailed view of size distribution.

Partial and whole mortality. Population dynamics were quantified by recording whether the specimens present in 1993 were alive or dead in 2007, and if alive, their fate. We considered whole mortality to occur in the year when the entire specimen had completely disappeared from the analyzed plot. In addition to whole mortality of specimens, events of partial mortality (the death of a ramet) were recorded every year, including the area of the dead ramet. In order to observe the effects of size on survivorship, the specimens were grouped into 3 size classes: I $\left(0-250 \mathrm{~mm}^{2}\right)$, II (250$\left.700 \mathrm{~mm}^{2}\right)$, and III $\left(>700 \mathrm{~mm}^{2}\right)$. These size classes were selected to encompass the size range encountered in the study site and to increase the number of measurements per group.

Fusion and fission events. A fission event was considered to have occurred when a single specimen fragmented into physically separate patches; a fusion event occurred when separated patches joined together, appearing as a single specimen for 2 consecutive years. For example, if a specimen split into 3 fragments or 3 fragments fused, 2 fission or fusion events would be recorded.

Recruitment. We estimated larval recruitment annually by monitoring the appearance of new specimens that were clearly not created by fission within the established permanent frames. Larval recruits were not easily identified from photographic frames, and to avoid confusion with small and orange 'points' of a different nature, we scored new recruits via larvae if they reached a minimal size $\left(\sim 1 \mathrm{~mm}^{2}\right)$ and survived $>1 \mathrm{yr}$, giving a conservative estimation of Crambe crambe recruitment. 
Growth rates. Growth of specimens was estimated as any change (gain or loss) in planar surface area from 1993 to 2007. Individual specimen areas as well as the summed areas of different ramets (resulting from fission and fusion processes) from the same specimen were recorded each year to give a single value per date. Growth measurements were performed only with the specimens that were alive during the entire study period. A total of 47 specimens were analyzed and classified at the beginning of the study into the 3 size classes: I $(\mathrm{N}=20)$, II $(\mathrm{N}=15)$, and III $(\mathrm{N}=12)$. Annual growth rate was calculated as:

$$
\left[A_{i}-A_{(i-1)}\right] / A_{i-1}
$$

where $A_{i}$ and $A_{(i-1)}$ are the area values at Year $i$ and the previous Year $(i-1)$, respectively. The outlines of the monitored patches were traced and their surface values were calculated using the program CPCe 3.4 (Kohler \& Gill 2006).

Statistics. The population structure of Crambe crambe at the beginning and end of the study was compared using the nonparametric KolmogorovSmirnov 2-sample test. Survival of the 133 specimens was analyzed using 'life tables' statistics (Fox 1993). Significant differences among size classes were estimated by 'Comparing Survival in Multiple Groups'. After that, comparisons between each pair of size classes were completed using the Gehan-Wilcoxon test. Chi-square contingency tables were used to compare frequency of partial and whole mortality as well as the frequency of fission and fusion events among years. This statistical test is unreliable with small expected values $(<5)$, so $2 \times 2$ frequency tables were used to compare frequencies (partial and whole mortality, fission and fusion) among size classes. Thus, the 3 size classes were pooled into 2 size categories: small (size class I) and large (size classes II and III).

In order to calculate changes on growth over time, a permutation method was used to test for differences through time and size classes. This test, based on Manly (1991), consisted of a 2-stage data permutation: first, individuals were randomly reassigned to the 3 size classes, then readings for each specimen were randomly rearranged among observation times. This permutation test was considered an adequate analysis since growth data did not comply with the circularity and homogeneity of variance-covariance matrix assumptions. The sum of squares associated with each factor and their interactions were then calculated as in standard ANOVAR analysis. This procedure was repeated 4999 times (plus the observed one) to obtain the frequency distribution of the sum of squares of each factor and its interactions. The val- ues of the statistics for the observed data were compared in these distributions. An effect was judged significant when the observed sum of squares was exceeded by $<5 \%$ of the corresponding values in the randomization series. If the permutation method denoted significant differences in growth, further analyses testing differences among size classes were performed. In these post hoc analyses, Bonferroni's correction was applied as different comparisons were calculated against the same distribution. Finally, a $t$ test for dependent variables was used to analyze differences in growth relative to size in 1993 and 2007, among the different size classes. Tests were computed using the program STATISTICA (version 6.0, StatSoft) and permutation tests were performed in a modified version of the Turbo Pascal program (Turon et al. 1998).

\section{RESULTS}

\section{Population structure}

Analyses of the permanent frames identified 133 genets and 157 ramets of Crambe crambe that could be tracked over 14 yr. Most ramets (75 and 80\%) were $<300 \mathrm{~mm}^{2}$ and few ( 7 and $15 \%$ ) were $>700 \mathrm{~mm}^{2}$ for both years 1993 and 2007, respectively. Additionally, 9 of the patches tracked were $>1000 \mathrm{~mm}^{2}$ in area in 2007. The frequency distribution of C. crambe did not vary considerably between 1993 and 2007 (Kolmogorov-Smirnov test, $\mathrm{p}=0.10$ ) (Fig. 2). Mean $\pm \mathrm{SE}$ patch

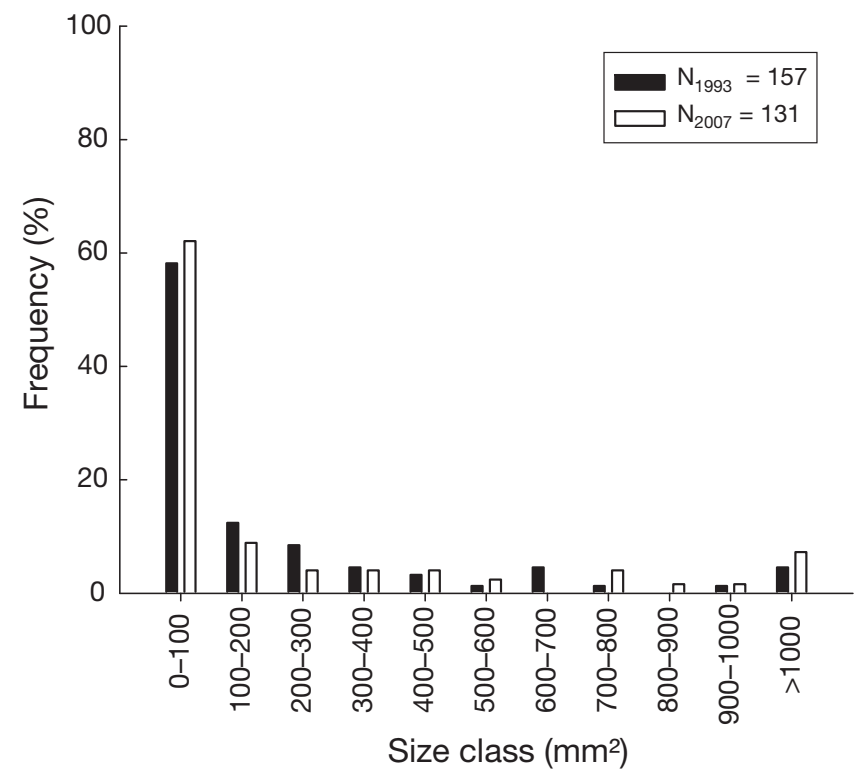

Fig. 2. Crambe crambe. Size-frequency distribution of ramets at the beginning (1993) and end (2007) of the study 


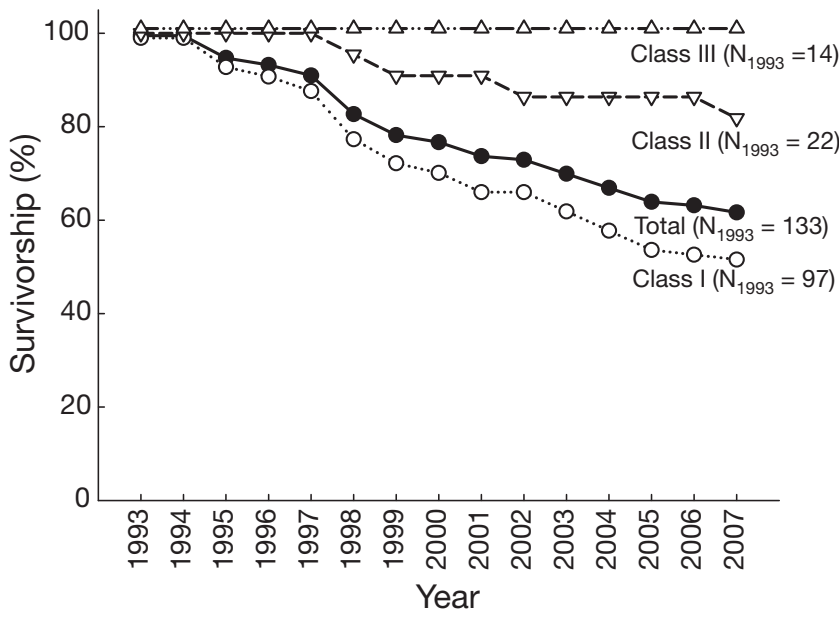

Fig. 3. Crambe crambe. Survivorship over $14 \mathrm{yr}$ at Pota de Llop. Data are for the whole population (black dots) and for 3 size classes (open symbols) as a function of their size in 1993. Size classes: I $\left(0-250 \mathrm{~mm}^{2}\right)$, II $\left(250-700 \mathrm{~mm}^{2}\right)$, III $\left(>700 \mathrm{~mm}^{2}\right)$

size ranged from $240 \pm 479 \mathrm{~mm}^{2}$ in 1993 to $328 \pm$ $800 \mathrm{~mm}^{2}$ in 2007.

\section{Survivorship}

After $14 \mathrm{yr}, 62 \%$ of the total population of Crambe crambe was still alive (82 out of 133 specimens survived) (Fig. 3). The lowest survivorship value (52\%) was recorded for specimens in size class I and differed significantly from the other 2 size classes (GehanWilcoxon test, $\mathrm{p}<0.001$ for both comparisons between each pair of size classes). Survivorship between size classes II and III was statistically indistinguishable over the study period $(p>0.05)$. No specimen (14) of the larger size class $\left(>700 \mathrm{~mm}^{2}\right)$ died during the study period (Fig. 3).

\section{Partial and whole mortality}

During the study period, 59 partial mortality events were recorded for 36 specimens with $>60 \%$ of them only suffering 1 event (Fig. 4A). The highest partial mortality value (6) was recorded for a specimen of size class III in $1993\left(723 \mathrm{~mm}^{2}\right)$ but the dead fragments were of small sizes (mean: $26.36 \pm 9.3 \mathrm{~mm}^{2}$ ) (Fig. 4B). Patterns of partial and whole mortality were significantly related to size $\left(2 \times 2\right.$ frequency tables, $\chi^{2}=35.6$, $\mathrm{df}=1, \mathrm{p}<0.0001$ for partial and $\chi^{2}=29.7$, df $=1, \mathrm{p}<$ 0.0001 for whole mortality). Small patches suffered both partial (mean area: $33.1 \pm 6.7 \mathrm{~mm}^{2}$ ) and whole mortality (mean area: $76.1 \pm 14.6 \mathrm{~mm}^{2}$ ) (Fig. 3B). Interestingly, no patch $>500 \mathrm{~mm}^{2}$ suffered any type of mortality over 14 yr. Overall, partial and whole mortality were low (annual mean: $3.9 \pm 0.75$ and $4 \pm 0.76$, respectively) and did not differ significantly among years (Appendix 2, available at www.int-res.com/articles/ suppl/m375p113_app.pdf) $\left(\chi^{2}=22.9, \mathrm{df}=13, \mathrm{p}>0.05\right.$ for partial and $\chi^{2}=27.3, \mathrm{df}=13, \mathrm{p}>0.05$ for whole mortality).

\section{Fission and fusion}

Table 1 shows the descriptive statistics of the asexual events recorded over $14 \mathrm{yr}$. A total of 53 monitored specimens underwent 118 fissions, while 25 specimens suffered 46 fusions (Table 1, Fig. 5). Approximately $60 \%$ of specimens were involved in only 1 event (Fig. 5). The maximum number of fission or fusion events observed for a single specimen during the $14 \mathrm{yr}$ was 7 fissions and 5 fusions, which occurred in specimens from the second and third size classes, respectively (Table 1, Fig. 5). Mean annual values for these asexual events were $8.4 \pm 0.9$ for fission and $3.3 \pm 0.5$ for fusion (Table 1). There was not a trend in asexual
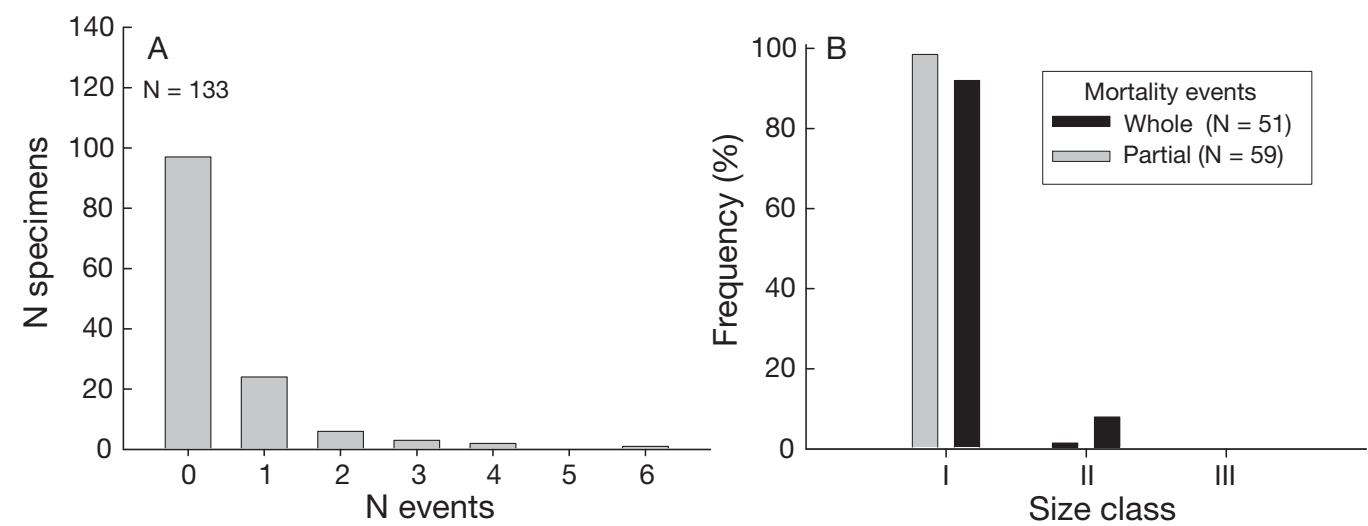

Fig. 4. Crambe crambe. (A) Total number of partial mortality events suffered by each specimen on the whole population under study. (B) Effect of size on partial and whole mortality. Size classes are defined in Fig. 2 
Table 1. Crambe crambe. (A) Fission and (B) fusion events for each size class (includes data calculated yearly and for all years combined). The mean annual probability of fission and fusion were determined by dividing the yearly number of specimens suffering the event by the total yearly population size. Patches were classified based on the 3 size classes before the asexual event. Numbers in parentheses are minimum and maximum values

\begin{tabular}{|c|c|c|c|c|}
\hline & Size I & Size II & Size III & All sizes \\
\hline \multicolumn{5}{|l|}{ (A) Fission } \\
\hline Mean \pm SE no. fissions specimen ${ }^{-1} \mathrm{yr}^{-1}$ & $\begin{array}{c}0.11 \pm 0.02 \\
\quad(0-3)\end{array}$ & $\begin{array}{c}0.17 \pm 0.04 \\
(0-4)\end{array}$ & $\begin{array}{c}0.25 \pm 0.04 \\
(0-3)\end{array}$ & $\begin{array}{c}0.16 \pm 0.02 \\
(0-4)\end{array}$ \\
\hline Mean \pm SE annual fissions specimen ${ }^{-1}$ & $\begin{array}{c}1.15 \pm 0.08 \\
(1-3)\end{array}$ & $\begin{array}{c}1.41 \pm 0.16 \\
(1-4)\end{array}$ & $\begin{array}{c}1.27 \pm 0.09 \\
(1-3)\end{array}$ & $\begin{array}{c}1.27 \pm 0.06 \\
(1-4)\end{array}$ \\
\hline Mean \pm SE no. fissions $\mathrm{yr}^{-1}$ & $\begin{array}{c}2.7 \pm 0.7 \\
(0-7)\end{array}$ & $\begin{array}{c}2.7 \pm 0.7 \\
(0-9)\end{array}$ & $\begin{array}{c}3.0 \pm 0.5 \\
(1-7)\end{array}$ & $\begin{array}{c}8.4 \pm 0.9 \\
(4-18)\end{array}$ \\
\hline Mean \pm SE no. fissions specimen ${ }^{-1}$ in $14 \mathrm{yr}$ & $\begin{array}{c}1.5 \pm 0.2 \\
(1-4)\end{array}$ & $\begin{array}{c}2.4 \pm 0.4 \\
(1-6)\end{array}$ & $\begin{array}{c}3.5 \pm 0.6 \\
(1-7)\end{array}$ & $\begin{array}{l}2.2 \pm 0.2 \\
(1-7)\end{array}$ \\
\hline Mean \pm SE size before fission $\left(\mathrm{mm}^{2}\right)$ & $\begin{array}{c}113.8 \pm 12.5 \\
(5-246)\end{array}$ & $\begin{array}{l}445.9 \pm 26.7 \\
(255.5-700)\end{array}$ & $\begin{array}{c}2591.4 \pm 688.9 \\
(700-9904.3)\end{array}$ & - \\
\hline Mean \pm SE size after fission $\left(\mathrm{mm}^{2}\right)$ & $\begin{array}{c}40.9 \pm 8.4 \\
(0.5-263.5)\end{array}$ & $\begin{array}{l}168.8 \pm 30.1 \\
(1.62-566.1)\end{array}$ & $\begin{array}{r}1224.8 \pm 555.8 \\
(9.9-10419.8)\end{array}$ & - \\
\hline Total no. specimens suffered fission in $14 \mathrm{yr}$ & 25 & 16 & 12 & 53 \\
\hline No. fragments formed by fission & 38 & 38 & 42 & 118 \\
\hline$\%$ of 1993 population & 25.8 & 72.7 & 85.7 & 39.9 \\
\hline Mean \pm SE annual probability of fission & $\begin{array}{l}0.04 \pm 0.01 \\
(0.00-0.12)\end{array}$ & $\begin{array}{l}0.14 \pm 0.03 \\
(0.00-0.41)\end{array}$ & $\begin{array}{l}0.21 \pm 0.03 \\
(0.07-0.50)\end{array}$ & $\begin{array}{c}0.08 \pm 0.008 \\
(0.03-0.14)\end{array}$ \\
\hline \multicolumn{5}{|l|}{ (B) Fusion } \\
\hline Mean \pm SE no. fusions specimen ${ }^{-1} \mathrm{yr}^{-1}$ & $\begin{array}{l}0.12 \pm 0.03 \\
\quad(0-2)\end{array}$ & $\begin{array}{c}0.15 \pm 0.05 \\
(0-3)\end{array}$ & $\begin{array}{c}0.13 \pm 0.04 \\
\quad(0-2)\end{array}$ & $\begin{array}{c}0.13 \pm 0.02 \\
(0-3)\end{array}$ \\
\hline Mean \pm SE annual fusions specimen ${ }^{-1}$ & $\begin{array}{c}1.06 \pm 0.06 \\
\quad(1-2)\end{array}$ & $\begin{array}{c}1.25 \pm 0.18 \\
(1-3)\end{array}$ & $\begin{array}{c}1.18 \pm 0.12 \\
(1-2)\end{array}$ & $\begin{array}{c}1.15 \pm 0.07 \\
(1-3)\end{array}$ \\
\hline Mean \pm SE no. fusions $\mathrm{yr}^{-1}$ & $\begin{array}{c}1.3 \pm 0.2 \\
(0-3)\end{array}$ & $\begin{array}{c}1.1 \pm 0.4 \\
(0-4)\end{array}$ & $\begin{array}{c}0.9 \pm 0.3 \\
(0-3)\end{array}$ & $\begin{array}{c}3.29 \pm 0.52 \\
\quad(1-7)\end{array}$ \\
\hline Mean \pm SE no. fusions specimen ${ }^{-1}$ in $14 \mathrm{yr}$ & $\begin{array}{c}1.6 \pm 0.2 \\
(1-3)\end{array}$ & $\begin{array}{l}2.1 \pm 0.6 \\
(1-5)\end{array}$ & $\begin{array}{c}1.9 \pm 0.6 \\
(1-5)\end{array}$ & $\begin{array}{c}1.84 \pm 0.33 \\
(1-5)\end{array}$ \\
\hline Mean $\pm \mathrm{SE}$ size before fusion $\left(\mathrm{mm}^{2}\right)$ & $\begin{array}{c}71.4 \pm 9.1 \\
(0.7-227.7)\end{array}$ & $\begin{array}{c}474.5 \pm 37.4 \\
(266.9-749.4)\end{array}$ & $\begin{array}{c}4282.8 \pm 1829.2 \\
(1492.5-10419.8)\end{array}$ & - \\
\hline Mean \pm SE size after fusion $\left(\mathrm{mm}^{2}\right)$ & $\begin{array}{l}870.4 \pm 367.5 \\
(6.1-10405.5)\end{array}$ & $\begin{array}{c}735.2 \pm 82.1 \\
(394.2-1394.4)\end{array}$ & $\begin{array}{l}4408.1 \pm 1775.4 \\
(1449.4-10405.5)\end{array}$ & - \\
\hline Total no. specimens suffered fusion in $14 \mathrm{yr}$ & 11 & 7 & 7 & 25 \\
\hline No. fragments fused & 18 & 15 & 13 & 46 \\
\hline \% of 1993 population & 11.3 & 31.8 & 50 & 18.80 \\
\hline Mean \pm SE annual probability of fusion & $\begin{array}{c}0.02 \pm 0.005 \\
(0.00-0.06)\end{array}$ & $\begin{array}{l}0.05 \pm 0.02 \\
(0.00-0.21)\end{array}$ & $\begin{array}{l}0.07 \pm 0.02 \\
(0.00-0.21)\end{array}$ & $\begin{array}{c}0.03 \pm 0.005 \\
(0.01-0.08)\end{array}$ \\
\hline
\end{tabular}

events among years $\left(\chi^{2}=21.8, \mathrm{df}=13, \mathrm{p}>0.05\right.$ for fission and $\chi^{2}=16.9, \mathrm{df}=13, \mathrm{p}>0.05$ for fusion) (Fig. 5). Overall, the mean annual probability of fission (0.04 \pm $0.01)$ and fusion $(0.02 \pm 0.03)$ was also relatively low. However, the relationship between size and the annual probability fission was significant $(2 \times 2$ frequency tables, $\chi^{2}=29.2$, df $=1, \mathrm{p}<0.0001$ ) (Table 1 ). This reflects specimens of the largest size class being almost 4 times more likely to undergo fission than the smallest specimens. Size of fragments before and after fission and fusion is presented in Table 1.

\section{Recruitment}

A total of 14 recruits were observed in a surface of $\sim 1 \mathrm{~m}^{2}$ during each year over the study period. Larval recruitment was low, oscillating between 0 (1995, 2001, 2003, 2004, and 2007) and 3 (2006). The mean value of larval recruitment was $0.9 \pm 0.26$ recruits $\mathrm{yr}^{-1}$. Survivorship among the recruits was almost $86 \%$ and 1 recruit survived $>10 \mathrm{yr}$ and was still alive in 2007 . The mean value of size in the first year of observation was $5.4 \pm 1.6 \mathrm{~mm}^{2}$. 

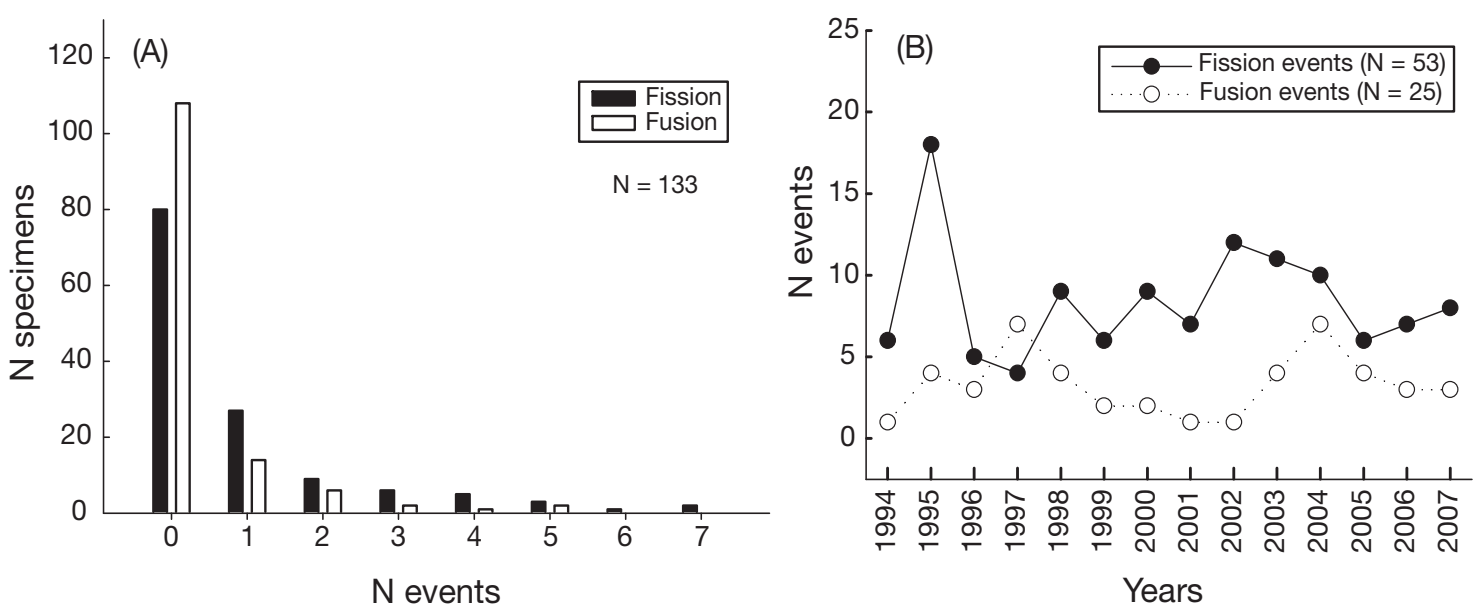

Fig. 5. Crambe crambe. (A) Total number of fission and fusion events suffered by each specimen. (B) Events suffered annually by the monitored specimens
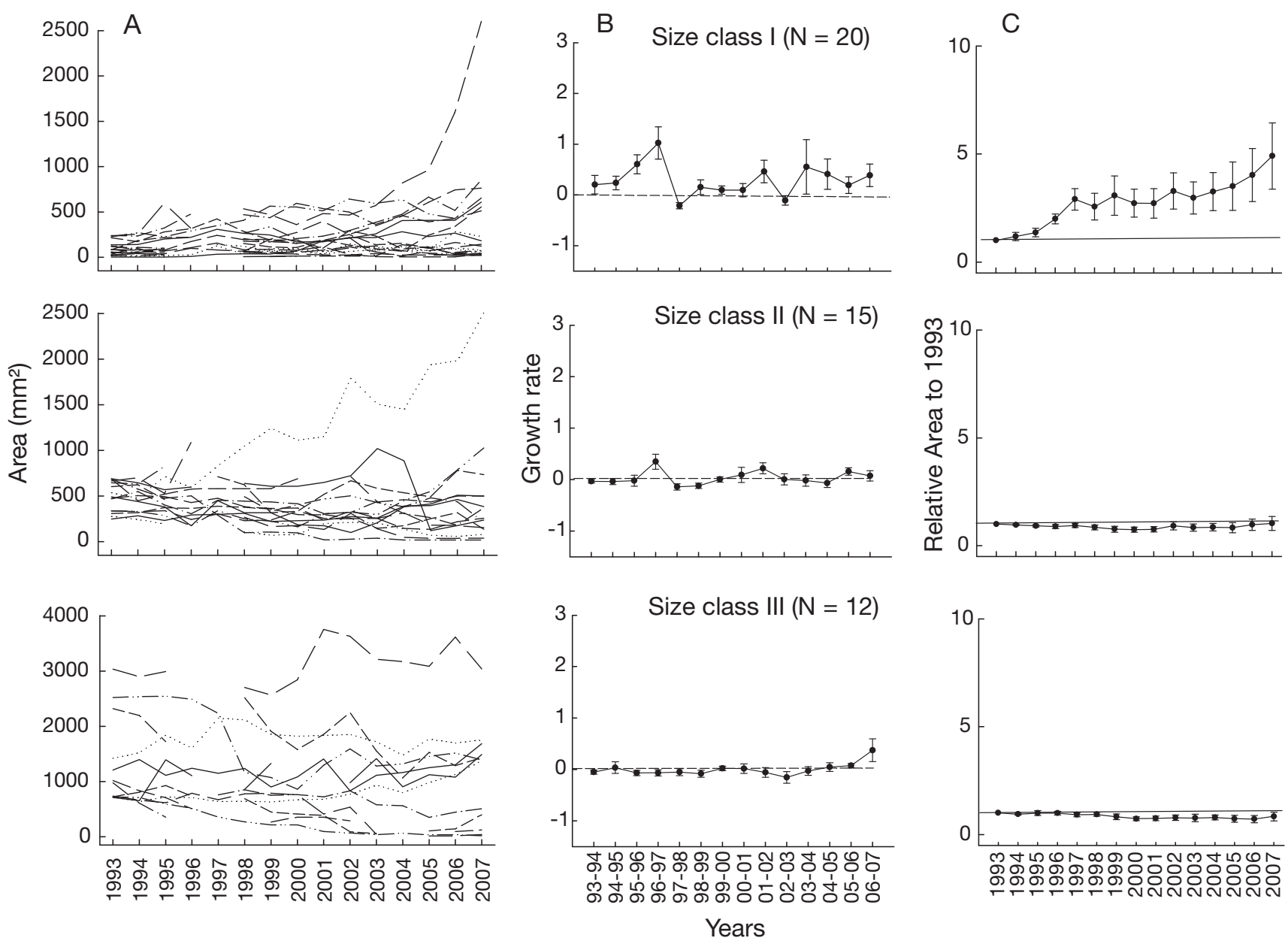

Fig. 6. Crambe crambe. (A) Changes in surface area, (B) yearly growth rate (mean \pm SE) and (C) relative area to 1993 of monitored specimens for 3 size classes from 1993 to 2007. Tendency of mean area $( \pm \mathrm{SE})$ of monitored specimens relative to their size in 1993 


\section{Growth}

Annual changes in the surface area of 47 specimens monitored from 1993 to 2007 are presented in Fig. 6A (see also Appendix 3, at www.int-res.com/ articles/suppl/m375p113_app.pdf). The data on surface area represents net growth measurements for each sampling period over 14 yr. Overall, we observed low and asynchronous growth in all specimens across the 3 size classes.

Small specimens (size class I) displayed moderate growth and a slight increase over time (mean values: $98 \pm$ $17 \mathrm{~mm}^{2}$ in 1993 and $383 \pm 132 \mathrm{~mm}^{2}$ in 2007), whereas larger specimens (size classes II and III) did not show any remarkable growth over the study period (Fig. 6A). Interestingly, out of the 20 small specimens, 1 showed remarkably fast growth, yielding a total increase of $\sim 600 \mathrm{~mm}^{2}$ in planar area over the $14 \mathrm{yr}$. Annual growth rates were also higher and more variable in size class I (total mean growth rate: $0.29 \pm 0.19 \mathrm{~mm}^{2}$ ) than in classes II and III (total mean growth rate: $0.03 \pm 0.09$ and $0.01 \pm 0.08 \mathrm{~mm}^{2}$, respectively) (Fig. 6B). The 2 latter classes show growth rates very close to zero, with neither growth nor loss of surface area.

No changes in (1) surface area, (2) annual growth rate, and (3) relative area of the initial size of Crambe crambe specimens were significantly different over the $14 \mathrm{yr}$ (for all permutation tests, $\mathrm{p}>0.05$ ). However, they were strongly related to size class $(p<0.0001)$ and each of the 3 size classes differed significantly from the others ( $p<0.0001$; paired comparisons after Bonferroni's correction). The interaction term (time $\times$ size class) was not significant for the 3 growth parameters. These results were not expected for the smallest size class as the faster growth of these specimens resulted in a net size increase of $\sim 4$-fold between 2007 and 1993 (Fig. 6C). Therefore, we tested change in area relative to initial size among the 3 size classes at the beginning (1993) and end (2007) of the study. The net area increase was significantly different for size class I ( $t$-test $=-2.4627 ; \mathrm{p}<0.01)$. This result may indicate that growth within size class I was not statistically conspicuous through time, but significant when comparing the initial (1993) and final (2007) survey periods.

\section{Processes affecting population size}

All processes seen to affect the population size of Crambe crambe over 14 yr are summarized in Table 2. C. crambe is a long-lived sponge; $60 \%$ of specimens of unknown age identified in 1993 were still alive $14 \mathrm{yr}$ later, and $85 \%$ of those newly recruited (mean age $6.3 \mathrm{yr}$ ) were still alive at the end of the study. Fission was a moderately important mechanism, depending on size class, occurring in $\sim 40 \%$ of the population (Table 1). However, $45 \%$ of these additional fragments were lost in partial mortality. Interestingly, most of partial mortality (91\%) affected small patches generated by fission. In contrast, fusion did not have a high impact on patch losses. At the end of the study in 2007, the net result was a $38 \%$ decrease in genet number and a $17 \%$ and decrease in ramet number, relative to 1993.

\section{DISCUSSION}

Relatively few demographic studies of long-lived, marine clonal sessile invertebrates consider sufficiently long time intervals to provide an accurate estimate of their demography (exceptions include Dayton 1979, Connell et al. 1997, Garrabou \& Harmelin 2002, Edmunds \& Elahi 2007). In our study population of Crambe crambe few dynamics were observed over $14 \mathrm{yr}$ (Table 2). The number of genets varied little over time (annual mean change: $3.6 \pm 0.76$ genets), their survival was high and recruitment via larvae was very low (mean: $0.9 \pm 0.26$ recruits $\mathrm{yr}^{-1}$ ). We did not detect mortality of large specimens despite their comparatively small size in relation to those encountered in the field and previously reported (Uriz et al. 1995, Turon et al. 1998). Overall, this population is mainly characterized by the inputs (fission) and outputs (fusion and partial mortality) of asexual ramets. Over $14 \mathrm{yr}$, the loss of ramets was approximately equal to the production of ramets by fission, so the number of patches remained relatively constant. Finally, we confirm that C. crambe grows slowly and exhibits long lifespans, which may encompass several decades. Based on a genetic study, 
Calderón et al. (2007) highlighted the importance of long-term demographic data to understand processes acting in the clonality and genetic structure of this species. To our knowledge, the present study is the first to provide solid long-term demographic data for this species, with observations spanning more than a decade. Our results may permit extrapolation, elucidating the general variation of this sponge's life history patterns at larger scales.

There were no apparent changes in population patterns of the abundance and size distribution after $14 \mathrm{yr}$ of study. Most patches belonged to small size classes $\left(<200 \mathrm{~mm}^{2}\right)$, with the largest size classes comprising a small percentage of the population in both 1993 and 2007 (Fig. 2). This pattern of relative constancy may result from the generally low dynamics of this species, where low mortality is accompanied by low growth and/or infrequent or unsuccessful recruitment events. This lack of recruitment is not due to the failure of larvae production, as specimens with a size range of 1 to $1000 \mathrm{~mm}^{2}$ include larvae (Uriz et al. 1995), but rather the low survival of juveniles (Uriz et al. 1998, De Caralt et al. 2007). During the $14 \mathrm{yr}$ study period, only $10 \%$ $(14 / 132)$ of newly recruited sponges resulted from sexually produced larvae and survived successfully. However, we acknowledge that in non-manipulated photographic frames, patches smaller than $\sim 1 \mathrm{~mm}^{2}$ are difficult to detect. Other factors also play a role in larval recruitment and juvenile survivorship: low larval recruitment and survival are frequently reported for sponges due to predation, competition for substrate, and physical perturbations (Battershill \& Bergquist 1990, Wulff 1991, Uriz et al. 1998). Mariani et al. (2005) identified filamentous and fast-growing algae proliferation as the main factor in recruit mortality for the bryozoan Schizobrachiella sanguinea. Overall, our findings are consistent with the overall paucity of sexual recruits in marine clonal organisms (Bak et al. 1981, Hughes \& Jackson 1985, Garrabou \& Harmelin 2002).

Survivorship was found to be relatively high and dependent on size (Fig. 3), with all the largest specimens surviving over the entire study period. In Crambe crambe, as in other sponges and benthic clonal animals, lower mortality of large individuals may result from the size-refuge effect, i.e. beyond a certain size, mortality decreases considerably (Connell 1973, Jackson 1979, Sebens 1982). The available photographs did not give direct evidence of the cause of mortality (damage by passing a sea urchin, sedimentation, etc.). Turon et al. (1998) suggested overgrowth by fast-growing algae to be the dominant factor of mortality in $C$. crambe. However, they reported survivorship values of only $60 \%$ over a 2 yr study of a population of larger individuals (mean size: $6886 \mathrm{~mm}^{2}$ ) dwelling in a shaded habitat but shallower than the one studied here. We attribute the higher survivorship observed in this study (annual mean: $~ 80 \pm 3.5 \%$ ) to habitat differences, as a variety of abiotic (e.g. hydrodynamics, food supply, irradiance, water temperature) and biotic factors (e.g. competition for space) may affect the observed dynamics of each population. Specifically, we hypothesize that space competition pressure may enhance survivorship and thus the persistence of this species in the population discussed here. As has been amply demonstrated, sponges must compete for space with other sponges and with many sessile organisms (Sarà 1970, Jackson \& Buss 1975, Aerts 2000, Wulff 2006). The study site is highly diversified and mainly dominated by perennial animals and algae species, which completely cover the space (Ros et al. 1984, Garrabou et al. 2002). C. crambe posses highly active metabolites (e.g. Jares-Erijman et al. 1991) and the production of chemical and physical defences increases in a space-saturated community (in dimly lit conditions) dominated by slow-growing animal species (Uriz et al. 1995, Becerro et al. 1997). In addition, Garrabou et al. (2002) found in the same study site a decrease in community turnover related with depth (5 to $20 \mathrm{~m}$ ), where species with the lowest growth rates were dwelling below $11 \mathrm{~m}$. Under this scenario, it seems likely that space competition pressure and the investment in production of allelochemicals and physical defences may explain the higher survivorship over longer time observed in the present study.

The relative contribution of sexual and asexual reproduction to the recruitment of new individuals into populations may vary considerably (Ayling 1980, Jackson \& Coates 1986, Karlson 2002). Both sexual and asexual inputs were relatively low over the $14 \mathrm{yr}$, and the great majority (>89\%) were formed vegetatively (Fig. 5, Table 1). Therefore, the population of Crambe crambe relied more on fission than sexual recruitment. The importance of asexual inputs is corroborated by genetic studies of population structure in this species (Calderón et al. 2007). However, it is important to note that $<40 \%$ and $20 \%$ of the population underwent fission and fusion, respectively, with a minor annual contribution to the studied population (mean probability of fission $\sim 0.1$ and of fusion $\sim 0.03$ annually) (Table 1). Our results agree with previous research (Turon et al. 1998, Garrabou \& Zabala 2001) demonstrating that fission in C. crambe is a comparatively moderate phenomenon compared with other sponges, which greatly relied on asexual mechanisms (values ranged from 97 to $72 \%$ ) (Wulff 1991, Teixidó et al. 2006, Blanquer 2007). Interestingly, fission may be related to partial mortality, as $\sim 50 \%$ of partial mortality of fragments occurred after a fission event and it was usual to observe fragments of $\sim 200 \mathrm{~mm}^{2}$ undergoing a size regression during the years prior to their death ( 2 to $4 \mathrm{yr}$ ) (Fig. 4 ). 
The decadal time-span and large number of individuals encompassed in the present study distinguish it from previous works analyzing population patterns of sponges. One of the most striking findings was the overall very slow growth pattern of Crambe crambe and the relatively high inter-individual variability of growth rate in the smallest specimens (Fig. 6A). This high variability has been noted in previous studies of clonal animal populations (Ayling 1983, Pansini \& Pronzato 1990, Wulff 1991, Turon \& Becerro 1992, Tanaka 2002). Small specimens exhibited the highest growth rates (net size increasing $\sim 4$ times in $14 \mathrm{yr}$ ) (Fig. 5C), which reinforces the size-refuge hypothesis as acting to reduce mortality. A similar relationship between growth pattern and size has been found in sponges (Dayton 1979, Pansini \& Pronzato 1990, Garrabou \& Zabala 2001) and some other clonal organisms (Bak et al. 1981, Hughes \& Jackson 1985, Garrabou \& Harmelin 2002).

Crambe crambe exhibits a seasonal pattern in lifehistory traits: e.g. maximum growth rates during summer and autumn, maximum investment in chemical defences in late autumn, and reproduction during summer (Uriz et al. 1995, Becerro et al. 1997, Turon et al. 1998, Garrabou \& Zabala 2001). Although studies over 2 yr reported seasonal growth and shrinkage patterns (Turon et al. 1998, Garrabou \& Zabala 2001), we show for the first time that net growth over more than a decade is close to zero for larger specimens. Moreover, this species exhibits a resting or dormant stage in late summer and autumn (Turon et al. 1999), when the site studied here is completely saturated by organisms, with strong competition with other animals and algae. This may indicate that although C. crambe exhibits seasonal growth and shrinkage peaks during an annual cycle, the result in the long term is a near lack of net growth.

Our 14 yr study gives the first evidence of the long lifespan of Crambe crambe. Based on the growth rates $\left(0.29 \mathrm{~mm}^{2} \mathrm{yr}^{-1}\right)$ and the size of the largest specimens found in this study $\left(\sim 3000 \mathrm{~mm}^{2}\right)$, we suggest that their age could represent several decades. Bearing in mind the relatively small sizes of sponges analyzed in this study compared to the maximum reported size (e.g. $0.5 \mathrm{~m}^{2}$ ), this estimation stresses the longevity of $C$. crambe and the role that may be played by episodic events. Age estimations from a $10 \mathrm{yr}$ study of Antarctic hexactinellid sponges suggested similarly long lifespans (several hundred years for specimens $80 \mathrm{~cm}$ in height) (Dayton 1979). However, new hexactinellid recruits with heights $>30 \mathrm{~cm}$ have recently been found on artificial panels (P. K. Dayton pers. comm.), suggesting that faster growth is possible. Another extreme example of this phenomenon is the prominent, longlived, columnar saguaro cactus Carneciea gigantean, which reproduces and grows episodically when a series of climatic and microhabitat conditions meet (Drezner 2006). Episodic favorable conditions may also induce successful recruitment and periods of fast growth in C. crambe. This prediction of 'windows of opportunity' has also been suggested for other longlived marine species with slow growth rates (Garrabou \& Harmelin 2002, Teixidó et al. 2006, Linares et al. 2007). Additionally, many long-lived marine sessile species recruit episodically and so their populations fluctuate on decadal or longer scales (Hughes \& Cancino 1985, Garrabou \& Harmelin 2002, Coma et al. 2004). The slow pace of these processes relative to the human lifespan can create errors in our perception of a population's history and our predictions for its future, as such projections are often based only on recent trends. In the summers of 1999 and 2003, mass mortality events of macroscopic sessile invertebrates dwelling in sublittoral habitats occurred in the NW Mediterranean Sea over several hundred kilometers (Cerrano et al. 2000, Perez et al. 2000). In these summers, sponges (among them C. crambe) and cnidarian populations suffered mortality outbreaks during high seawater temperature anomalies (Cerrano et al. 2000, Perez et al. 2000, 2004). These mortality events involving slow-growing invertebrates reinforce and lend urgency to the need for long-term data sets and field observations at different spatial scales to foresee widespread population responses of long-lived sessile species under threat from climate change.

Acknowledgements. We thank N. Bensoussan, O. Bianchimani, C. Linares, M. Zabala, and many persons who accompanied us in this field study since its start in 1993. Special recognition is due to R. Graille and F. Zuberer for all the technical support in modernizing the photographic equipment. We also thank N. Boury-Esnault, R. Coma, S. De Caralt, and J. Vacelet for their helpful comments and fruitful discussions. R. Pronzato and 3 anonymous reviewers provided invaluable comments on an earlier draft. N.T. was partially funded by a Marie Curie Intra-European Fellowship (FP6 no. 010726) and the Reintegration Grant Mechanisms (FP7 no. 207632). This study was funded by Direcció General de Pesca Marítima (Generalitat de Catalunya) project no. PCC68003/9, Direcció de Medi Natural (Generalitat de Catalunya) project no. 10.05.227.07/5, and the Agence National de la Recherche (Medchange project).

\section{LITERATURE CITED}

Adondakis S, Venable DL (2004) Dormancy and germination in a guild of sonoran desert annuals. Ecology 85: $2582-2590$

Aerts LAM (2000) Dynamics behind standoff interactions in three reef sponge species and the coral Montastrea cavernosa. PSZN I: Mar Ecol 21:191-204

Ayling AL (1980) Patterns of sexuality, asexual reproduction and recruitment in some subtidal marine Demospongiae. Biol Bull (Woods Hole) 158:271-282 
Ayling AL (1983) Growth rates and regeneration in thinly encrusting Demospongiae from temperate waters. Biol Bull (Woods Hole) 165:343-352

Bak RPM, Sybesma J, Van Duyl FC (1981) The ecology of the tropical compound ascidian Trididemnum solidum. II. Abundance, growth and survival. Mar Ecol Prog Ser 6: 43-52

Battershill CN, Bergquist PR (1990) The influence of storms on asexual reproduction, recruitment, and survivorship of sponges. In: Rützler K (ed) New perspectives in sponge biology. Smithsonian Institution Press, Washington, DC, p 397-403

Becerro MA, Uriz MJ, Turon X (1997) Chemically-mediated interactions in benthic organisms: the chemical ecology of Crambe crambe (Porifera, Poecilosclerida). Hydrobiologia 355:77-89

Bergquist PR (1978) Sponges. University of California Press, Berkeley, CA

Blanquer A (2007) Molecular markers for phylogenetic and population studies of the genus Scopalina (Porifera: Demospongiae). PhD dissertation, University of Barcelona

Boury-Esnault N (1971) Spongiaires de la zone rocheuse littorale de Banyuls-sur-Mer. I. Ecologie et répartition. Vie Milieu 22:159-192

Calderón I, Ortega N, Duran S, Becerro M, Pascual M, Turon $X(2007)$ Finding the relevant scale: clonality and genetic structure in a marine invertebrate (Crambe crambe, Porifera). Mol Ecol 16:1799-1810

> Cerrano C, Bavestrello G, Bianchi CN, Cattaneo-Vietti R and others (2000) A catastrophic mass-mortality episode of gorgonians and other organisms in the Ligurian Sea (NW Mediterranean), summer 1999. Ecol Lett 3:284-293

Coma R, Pola E, Ribes M, Zabala M (2004) Long-term assessment of the patterns of mortality of a temperate octocoral in protected and unprotected areas: a contribution to conservation and management needs. Ecol Appl 14: 1466-1478

Connell JH (1973) Population ecology of reef building corals. In: Jones OA, Endean R (eds) Biology and geology of corals reefs, Vol 2. Academic Press, New York, p 205-245

Connell JH, Hughes TP, Wallace CC (1997) A 30-year study of coral abundance, recruitment, and disturbance at several scales in space and time. Ecol Monogr 67:461-488

Dayton PK (1979) Observations of growth, dispersal and population dynamics of some sponges in McMurdo Sound, Antarctica. Colloq Int CNRS 291:271-282

> De Caralt S, Otjens H, Uriz MJ, Wijffels RH (2007) Cultivation of sponge larvae: settlement, survival, and growth of juveniles. Mar Biotechnol 9:592-605

> Drezner TD (2006) Regeneration of Carnegiea gigantea (Cactaceae) since 1850 in three populations in the northern Sonoran Desert. Acta Oecol 29:178-186

> Duran S, Giribet G, Turon X (2004) Phylogeographical history of the sponge Crambe crambe (Porifera, Poecilosclerida): range expansion and recent invasion of the Macronesian islands from the Mediterranean Sea. Mol Ecol 13:109-122

$>$ Edmunds PJ, Elahi R (2007) The demographics of a 15-year decline in cover of the Caribbean reef coral Montastraea annularis. Ecol Monogr 77:3-18

Eriksson O (1993) Dynamics of genets in clonal plants. Trends Ecol Evol 8:313-316

Fox GA (1993) Failure-time analysis: emergence, flowering, survivorship, and other waiting times. In: Scheiner SM, Gurevitch J (eds) Design and analysis of ecological experiments. Chapman \& Hall, London, p 113-137

> Garrabou J, Harmelin JG (2002) A 20-year study on life-history traits of a harvested long-lived temperate coral in the
NW Mediterranean: insights into conservation and management needs. J Anim Ecol 71:966-978

Garrabou J, Zabala M (2001) Growth dynamics in four Mediterranean desmosponges. Estuar Coast Shelf Sci 52: 293-303

> Garrabou J, Ballesteros E, Zabala M (2002) Structure and dynamics of north-western Mediterranean rocky benthic communities along a depth gradient. Estuar Coast Shelf Sci 55:493-508

Gili JM, Ros JD (1985) Study and cartography of benthic communities of Medes Islands (NE Spain). PSZN I: Mar Ecol 6: $219-238$

Hall VR, Hughes TP (1996) Reproductive strategies of modular organisms: comparative studies of reef-building corals. Ecology 77:950-963

Harper JL (1977) Population biology of plants. Academic Press, London

Hughes RN (1989) A functional biology of clonal animals. Chapman \& Hall, London

Hughes RN, Cancino JM (1985) An ecological overview of cloning in metazoa. In: Jackson JBC, Buss LW, Cook RE (eds) Population biology and evolution of clonal organisms. Yale University Press, New Haven, CT, p 153-186

Hughes TP, Jackson JBC (1985) Populations dynamics and life histories of foliaceus corals. Ecol Monogr 55:141-166

Jackson JBC (1979) Morphological strategies of sessile animals. In: Larwood G, Rosen BR (eds) Biology and systematics of colonial organisms. Academic Press, London, p 499-555

Jackson JBC, Buss L (1975) Allelopathy and spatial competition among coral reef invertebrates. Proc Natl Acad Sci USA 72:5160-5163

> Jackson JBC, Coates AG (1986) Life cycles and evolution of clonal (modular) animals. Philos Trans R Soc Lond B 313: $7-22$

Jares-Erijman E, Sakai R, Rinehart KL (1991) Crambescidins: new antiviral and cytotoxic compounds from the sponge Crambe crambe. J Org Chem 56:5712-5715

Karlson RH (2002) Population processes in modular benthic invertebrates. In: Hughes RN (ed) Reproductive biology of invertebrates, Vol XI. Progress in asexual reproduction. John Wiley \& Sons, Chichester, p 255-282

Kohler KE, Gill SM (2006) Coral Point Count with Excel extensions (CPCe): a Visual Basic program for the determination of coral and substrate coverage using random point count methodology. Comput Geosci 32:1259-1269

> Leys SP, Lauzon NRJ (1998) Hexactinellid sponge ecology: growth rates and seasonality in deep water sponges. J Exp Mar Biol Ecol 230:111-129

Linares C, Doak DF, Coma R, Díaz D, Zabala M (2007) Life history and viability of a long-lived marine invertebrate: the octocoral Paramuricea clavata. Ecology 88:918-928

Manly BFJ (1991) Randomization and Monte Carlo methods in biology. Chapman \& Hall, London

> Mariani S, Alcoverro T, Uriz MJ, Turon X (2005) Early life histories in the bryozoan Schizobrachiella sanguinea: a case study. Mar Biol 147:735-745

> Miriti MN (2007) Twenty years of changes in spatial association and community structure among desert perennials. Ecology 88:1177-1190

Pansini M, Pronzato R (1990) Observations on the dynamics of a Mediterranean sponge community. In: Rützler K, Macintyre V, Smith K (eds) New perspectives in sponge biology. Smithsonian Institution Press, Washington, DC, p 404-415

Perez T, Garrabou J, Sartoretto S, Harmelin JG, Francour P, Vacelet J (2000) Mortalité massive d'invertébrés marins: un événement sans précédent en Méditerranée nord-occidentale. CR Acad Sci Paris III 323:853-865 
Perez T, Massias D, Harmelin JG (2004) Mise à jour des inventaires d'invertébrés de substrats durs (Spongiaires, Bryozoaires) à Monaco et suivis d'indicateurs biologiques. Contrat Direction de l'Environnement de la Principauté de Monaco \& GIS Posidonie - COM, Marseille

Pronzato R, Manconi R (1995) Long-term dynamics of a freshwater sponge population. Freshw Biol 33:485-495

Rees M, Condit R, Crawley M, Pacala S, Tilman D (2001) Long-term studies of vegetation dynamics. Science 293: 650-654

Ros J, Olivella I, Gili JM (1984) Els sistemes naturals de les Illes Medes. Arxius Secció Ciències 73. Institut d'Estudis Catalans, Barcelona

Sarà M (1970) Competition and cooperation in sponge populations. Symp Zool Soc Lond 23:273-284

Schmidt O (1862) Die Spongien des Adriatischen Meeres. Verlag von Wilkelm Engelmann, Leipzig

Sebens KP (1982) Intertidal distribution of zoanthids on the Caribbean coast of Panama: effects of predation and desiccation. Bull Mar Sci 32:316-335

Silander JA (1985) Microevolution in clonal plants. In: Jackson JBC, Buss LW, Cook RE (eds) Population biology and evolution of clonal organisms. Yale University Press, New Haven, CT, p 107-152

Stephenson NL (1994) Long-term dynamics of sequoia populations: implications for managing a pioneer species. In: Aune PS (ed) Conference on giant sequoias: their place in the ecosystem and society. USDA Forest Service, General Technical Report PSW-GTR-151, p 56-63

Tanaka K (2002) Growth dynamics and mortality of the intertidal encrusting sponge Halichondria okadai (Demospongiae, Halichondria). Mar Biol 140:383-389

Tanner JE (2001) The influence of clonality on demography: patterns in expected longevity and survivorship. Ecology 82:1971-1981

Teixidó N, Gili JM, Uriz MJ, Gutt J, Arntz WE (2006) Observations of asexual reproductive strategies in Antartic

Editorial responsibility: Laura Airoldi,

Ravenna, Italy hexactinellids sponges from ROV video records. Deep-Sea Res II 53:972-984

Turon X, Becerro MA (1992) Growth and survival of several ascidian species from the northwestern Mediterranean. Mar Ecol Prog Ser 82:235-247

Turon X, Becerro MA, Uriz MJ (1996) Seasonal patterns of toxicity in benthic invertebrates: the encrusting sponge Crambe crambe (Poecilosclerida). Oikos 75:33-40

> Turon X, Tarjuelo I, Uriz MJ (1998) Growth dynamics and mortality of the encrusting sponge Crambe crambe (Poecilosclerida) in contrasting habitats: correlation with population structure and investment in defence. Funct Ecol 12: $631-639$

Turon X, Uriz MJ, Willenz P (1999) Cuticular linings and remodelisation processes in Crambe crambe (Demospongiae: Poecilosclerida). Mem Queensl Mus 44:617-625

Uriz MJ, Rosell D, Martin D (1992) The sponge population of the Cabrera archipelago (Balearic Islands): characteristics, distribution and abundance of the most representative species. PSZN I: Mar Ecol 13:101-117

Uriz MJ, Turon X, Becerro M, Galera J, Lozano J (1995) Patterns of resource allocation to somatic, defensive, and reproductive functions in the Mediterranean encrusting sponge Crambe crambe (Demospongiae, Poecilosclerida). Mar Ecol Prog Ser 124:159-170

Uriz MJ, Maldonado M, Turon X, Marti R (1998) How do reproductive output, larval behaviour, and recruitment contribute to adult spatial patterns in Mediterranean encrusting sponges? Mar Ecol Prog Ser 167:137-148

Voultsiadou E (2005) Demosponge distribution in the eastern Mediterranean: a NW-SE gradient. Helgol Mar Res 59: $237-251$

Wulff JL (1991) Asexual fragmentation, genotype success, and populations dynamics of erect branching sponges. J Exp Mar Biol Ecol 149:227-247

> Wulff JL (2006) Ecological interactions of marine sponges. Can J Zool 84:146-166

Submitted: April 9, 2008; Accepted: September 23, 2008

Proofs received from author(s): December 22, 2008 